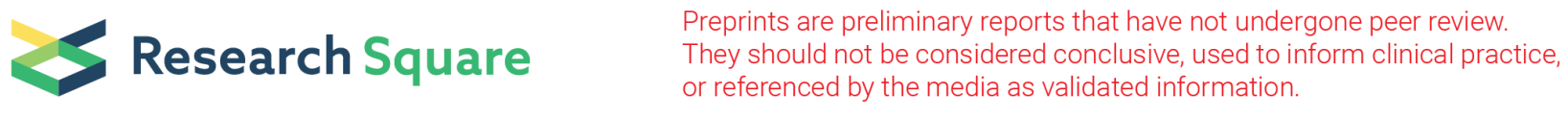

\title{
Short-Term and Long-Term Effects of Social Isolation on Health Outcomes among Older People in China
}

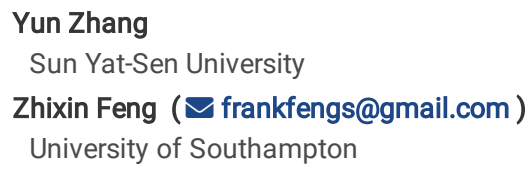

\section{Research Article}

Keywords: Social isolation, Loneliness, Cognition, Activities of daily living, Longevity, Health aging

Posted Date: March 12th, 2021

DOI: https://doi.org/10.21203/rs.3.rs-283277/v1

License: @ (i) This work is licensed under a Creative Commons Attribution 4.0 International License. Read Full License 


\section{Abstract}

Background Social isolation and loneliness are serious public health risks affecting a significant number of older adults globally. However, it is uncertain whether their health effects are short-term or long-term, which impedes the developing of more effective and precising interventions. We therefore assessed the varied health effects of short-term and long-term exposure of social isolation and loneliness among a nationwide sample of older adults from China.

Methods We assessed social isolation and loneliness in 6,066 men and women aged 65 and older who took part in both 2011 and 2014 waves of Chinese Longitudinal Healthy Longevity Survey. Social isolation was assessed in terms of absence of key family members, including spouse, children or siblings, and a deficiency in participating in social activities. Loneliness was administered by using a questionnaire. Four health outcomes were investigated: self-rated health, activities of daily living (ADLs), Instrumental activities of daily living (IADLs), and cognitive function measured by Mini-Mental State Examination (MMSE). We used different tests and multivariate regression analyses to examine the short-term ( $<3$ years) and long-term (>= 3 years) effects of social isolation and loneliness on health outcomes.

Results After controlling for covariates of demographic, socioeconomic, lifestyle, and baseline health factors, in the short-term effects, there are significant associations found between absence of children and poor SRH and cognitive impairment (ORs=1.53 and 9.87); absence of siblings and poor SRH, cognitive impairment, and difficulty with ADLs and IADLs (ORs=1.29, 1.35, 1.26 and 1.22 respectively); loneliness and poor SRH and difficulties with IADLs (ORs=1.92 and 1.55). While, in the long-term effects, absence of siblings is marginally significantly associated with cognitive impairment (OR=1.21), but significant associations are found between deficiency in participating in social activities and poor SRH, difficulty with ADLs and IADLs (ORs=1.33, 1.55 and 1.69, respectively); loneliness and poor $\mathrm{SRH}$, difficulty with IADLs and less difficulties in ADLs (ORs=2.96, 2.45 and 0.32, respectively).

Conclusions The results of this study show that social isolation at family level mainly have short-term effects, while social isolation at societal level have mainly have long-term, and loneliness has both short-term and long-term effects on older people's health outcomes.

\section{Highlights}

1. Social isolation at family level (measured as the absence of key family members) mainly have short-term effects rather than long-term effects on older people's health outcomes.

2. Social isolation at societal level (measured as deficiency in participating in social activities) mainly have long-term impacts on older people's health outcomes.

3. Loneliness had both short-term and long-term effects on poor SRH and difficulty with IADLs.

\section{Introduction}

China has the largest ageing population in the world. Traditionally, the family network is the most important source of social support for older people in China (Li \& Zhang, 2015). However, with the transition of the traditional family structure, the number of traditional multigenerational households is decreasing rapidly. As a consequence, there are fewer potential extended family members to personally support older adults through co-residence (Phillips \& Feng, 2015). Older people in China are encountering decreasing social connections with family members, and social isolation is becoming one of the most disadvantageous conditions for them. In addition, the rapid spread of COVID-19 has forced most countries to implement social distancing restrictions. According to the World Health Organization's statement, older people are at the highest risk from COVID-19 (Kluge, 2020). Social isolation is one effect of implementing social distancing restrictions to prevent older people from being infected with COVID-19; meanwhile, the costs of social isolation cannot be ignored as it also raises health-related issues (Douglas, 2020).

\section{Social Isolation as a Risk Factor of Health}

Social isolation can be defined as "a state in which the individual lacks a sense of belonging socially, lacks engagement with others, has a minimal number of social contacts and they are deficient in fulfilling and quality relationships" (Nicholson, 2009). In general, social isolation is considered as a major risk factor of health which leads to numerous detrimental health conditions for older adults, such as depression, cardiovascular disease, and coronary heart disease or stroke (Berkman, 1984; Boden-Albala et al., 2005). Studies suggest that greater social connections may foster a sense of "coherence" or meaning and purpose in life (Antonovsky, 1987), while poor social connections increase the risk of cognitive decline and death from suicide (Beland et al., 2005; Eng et al., 2002). More specifically, social isolation has objective and subjective dimensions. Although these two dimensions are frequently correlated, they are not in the same construct (Taylor et al., 2018). Both dimensions of social isolation could generally have detrimental effects on health outcomes by various pathways

(Cacioppo et al., 2015).

\section{Objective Social Isolation and Health}

Objective social isolation refers to objective features of the social environment which contribute to a low quantity of social relationships (Cacioppo et al., 2015), such as the absence of a spouse, children, or siblings, and/or having no participation in organizations, clubs, or religious groups (Berkman, 1983; Howat et al., 2004; House et al., 1988). Objective social isolation has been suggested to be associated with morbidity and mortality through pathways of health behaviours. Family members encourage individuals to exhibit good, healthy behaviours such as diet, exercise, leisure activities, and compliance with medical regimens, and discourage individuals from health-damaging behaviours such as smoking and drinking (House, 2001). Therefore, older people who do not have a spouse or children to live with could be more likely to develop unhealthy lifestyles, and this might gradually result in deteriorating health status (Feng, 2018). Objective social isolation could also affect older people's health in psychological ways. For example, the loss of a family member, especially an adult child, could be a heavy strike for older people, which causes feelings of helplessness and hardship (Chen et al., 2019). However, other studies also suggest that objective social isolation may not actually have detrimental effects on health outcomes. For example, poor-quality marriages have been found to

Page $2 / 11$ 
be associated with compromised immune and endocrine function and depression (Kiecolt-Glaser et al., 2001). Similarly, taking part in social activities may reduce the risk of depression among older individuals, but it also may increase the risk of getting injuries. Older people who stay at home with a sedentary lifestyle could avoid and prevent the potential risks of getting hurt from taking part in social activities (Wang et al., 2020).

\section{Subjective Social Isolation and Health}

Subjective social isolation, or loneliness reflects the distressing feeling of social isolation that accompanies the perception of deficiency in the desired number or quality of one's social relationships (Peplau \& Perlman, 1982; Gierveld \& Van Tilburg, 2006), Subjective social isolation, or loneliness could be a stressor to individuals, which can influence their physiological processes by chronically affecting the immune, neuroendocrine, and cardiovascular systems, and increasing allostatic load (McEwen, 1998; Hartigan et al., 2019; Seeman et al., 2002). It has been found that older people who perceive themselves to be socially isolated or loneliness are more likely to develop heart disease or stroke (Boden-Albala et al., 2005). Subjective social isolation can also affect one's mental health, which is not only associated with depression but also a pivotal mechanism that works in concert with each of the other mechanisms to shape physical health (Chapman et al., 2005). Additionally, subjective social isolation has been found to predict increased morbidity and mortality, even after adjusting for objective social isolation and health behaviours, which suggests that subjective social isolation could be a more important factor in health than the objective social isolation for older people (Cacioppo et al., 2015; Hartigan et al., 2019).

In China, family network is the most important source of social support for older people (Li \& Zhang, 2015). However, the transition of the traditional family structure and long distance rural-to-urban migration in China has changed the patterns of living arrangements and impaired the cohesion of family ties: older people could experience strengthened loneliness. In addition, the one child policy has led to a new phenomenon of "childless" older people (Feng, 2018), and rapid urbanization and modernization have turned the societal of acquaintances into the societal of strangers - which means that the chance of social isolation of older people in China is also rising. Therefore, the social isolation of older people and its health consequences are of increasing concern.

This paper investigates the short-term and long-term effects of objective and subjective social isolation on various health outcomes, by integrating two waves of longitudinal survey datasets. The baseline of and change in objective and subjective isolation status between two waves are used to predict health outcomes at Wave 2. First, short-term social isolation is defined as the change in social isolation between two waves, from not being socially isolated at Wave 1 (2011) to being social isolated at Wave 2 (2014). We explore the effect of becoming socially isolated on health outcomes at Wave 2 . Second, by defining long-term social isolation as the status of people who were socially isolated at Wave 1, we examine the long-term effects of social isolation on health outcomes at Wave 2. The research strategy gives a panoramic picture of the likely mechanisms between social isolation and health outcomes. It could provide a better understanding of the impact of social isolation on health from a short-term and long-term perspectives. It will be valuable to achieve better development and targeting of appropriate health promotion programmes for older people who are being or have been social isolated.

\section{Data And Method}

\section{Data and Sampling}

This study used the dataset of the 2011-2014 Chinese Longitudinal Healthy Longevity Survey (CLHLS). CLHLS is a longitudinal survey dataset of a nationally representative sample of Chinese people aged 65 and above, using internationally compatible questionnaires (Zeng et al., 2017). It covers 23 out of 31 provinces in China which covers 85 percent of the total population in China. It collected extensive data on a large population of the oldest-old aged $80-112$ with comparatively younger elders aged 65-79. There were 9,765 respondents in 2011 . Among these respondents, a total of 820 ( $8 \%$ ) respondents were lost to follow-up in 2014, while 2,879 (29\%) respondents died before the 2014 survey. The final sample included a total of 6,066 respondents with valid information in two waves.

\section{Dependent Variables}

Self-rated health, cognitive health, activities of daily living (ADLs), and instrumental activities of daily living (IADLs) were considered in this study (See Table 1). Self-rated health (SRH) is a comprehensive evaluation of the overall health status of older people. There were five categories: very good, good, fair, poor, and very poor. It was recoded into a binary variable: 0 for very good and good, and 1 for very poor, poor and fair (i.e. Sereny and Gu, 2011). Cognitive health was measured by the Chinese version of the Mini Mental State Examination (MMSE), in which four aspects of mental functioning were tested: orientation, calculation, recall, and language. The maximum score for the MMSE was 30; lower scores indicated more severe cognitive problems. According to previous studies, a score of 18 was used as cut-off point (Nguyen et al., 2003; Zhang, Zahner, \& Roman et al., 2006; Zhang, Gu, \& Hayward, 2010); respondents with MMSE scores of less than 18 were defined as having "cognitive impairment" in this study (coded as 1 ), and the rest were defined as "non-cognitive impairment" (coded as 0). Activities of daily living (ADLs) and instrumental activities of daily living (IADLs) were used as functional health status. Difficulty with ADLs is commonly used to gauge older people's daily performance, and it includes six basic activities: bathing, dressing, eating, using the toilet, free movement, and controlling urine and defecation. For comparability with previous studies (i.e. Evandrou et al., 2014; Feng, 2018), a binary variable was constructed for ADLs with 1 representing difficulty with any of the six ADLs, and 0 representing "no" difficulty with any of the six ADLs. The indicator of IADLs include eight items: visiting neighbours, going shopping, making food, washing clothes, walking one kilometre, carrying $5 \mathrm{~kg}$ weight, crouching and standing three times, and taking public transportation. Similarly, a binary variable was constructed for IADLs with 1 representing having difficulty with any of the eight IADLs, and 0 representing having no difficulty with any of the eight IADLs. All health outcomes were measured in the 2014 datasets.

\section{Independent Variables}

In this paper, social isolation included two dimensions: objective social isolation and subjective social isolation (See Table 1). For objective social isolation, we considered the potential context at both family and societal level. Spouse, children and siblings are crucial members and networks within a family, thus living without a spouse (separated, widowed, divorced, or never married), having no surviving children, and having no surviving siblings were the most substantial external conditions at family level leading to the social isolation of older people. Moreover, participating in social activities at societal level could provide 
opportunities for people to become involved in their community and for the family to maintain or develop supportive and caring relationships (World Health Organization, 2007). Thus, a deficiency in participating in social activities is used as the measurement of objective social isolation at societal level. Therefore, the criteria for objective social isolation in this study included being "spouseless", "childless", "has no surviving siblings", and "does not participate in social activities".

In terms of subjective social isolation, respondents were asked the frequency "always", "often", "sometimes", "seldom", or "never" for the question "do you often feel lonely and isolated". This question reflects the absence of feelings of belonging and having fulfilling relationships, and it is consistent with established papers that have broadly taken that loneliness as an indicator of subjective social isolation (Nicholson, 2009). We recoded these five categories into a binary variable: 0 (not lonely) for seldom, never and sometimes, and 1 (feel lonely) for always and often.

As mentioned in the introduction, short-term social isolation was defined as the change in social isolation between two waves, from not being socially isolated at Wave 1 (2011) to being socially isolated at Wave 2 (2014). Long-term social isolation was measured at Wave 1 and analysed in terms of how this was associated with health outcomes at Wave 2 . Since less than one per cent of older adults who were socially isolated at Wave 1 became not being socially isolated at Wave 2 and the effects of such changes were not significantly associated with one's health outcomes; therefore, we assumed social isolation statuses of those older adults who were socially isolated at Wave 1 were consistent between two waves.

\section{Covariates}

Although the focus of this paper was on the effects of social isolation on health, it is important to control for other factors so that the effects are reliable. Demographic, socioeconomic, and lifestyle characteristics were used, including age, gender, self-rated socioeconomic status (SES), education level, urban/rural residence, smoking, drinking, frequency of leisure activities, and physical exercise were used as control variables following previous reports (Zeng et al., 2017). All covariates were measured in 2011 (See Table 1). We also used all health outcomes in the 2011 as covariates.

\section{Method}

Logistic regression models were applied to differentiate the effects of social isolation on health outcomes. For both the short-term and long-term effects of social isolation on health outcomes, there were two models: Model 1 included only objective social isolation and subjective social isolation variables, in order to explore their direct effects on health outcomes, whereas Model 2 added covariates to investigate whether the effects of social isolation on health outcomes were mediated by these factors.

\section{Results}

\section{Descriptive Statistics}

The detailed descriptive statistics for all variables in this paper are summarized in Table 1. The proportions of older people who report poor SRH, cognitive impairment, difficulty in ADLs, and difficulty in IADLs in 2014 are $59.0 \%, 23.0 \%, 24.4 \%$, and $63.4 \%$, respectively. In terms of the short-term social isolation, 3.7\% of older people became spouseless in $2014,2.6 \%$ of older people become childless, around one tenth of older people ceased to have siblings, around $7 \%$ of older people withdrew from social activities, and $3.2 \%$ of older people felt lonely in 2014 . In terms of the long-term social isolation, $51.6 \%$ of older people were already spouseless, $2.1 \%$ were already childless, and $30.9 \%$ already had no siblings in $2011.71 .6 \%$ of older people did not participate in social activities and $1.0 \%$ of older people reported loneliness in 2011. 


\begin{tabular}{|c|c|c|c|}
\hline Variable & Description & Coding & $\begin{array}{l}\text { Percentage/Mean } \\
(\mathrm{N}=6,066)\end{array}$ \\
\hline \multicolumn{4}{|c|}{ Dependent variable (Health outcomes in 2014) } \\
\hline \multirow[t]{2}{*}{$\begin{array}{l}\text { Self-reported } \\
\text { health (SRH) }\end{array}$} & \multirow[t]{2}{*}{ It originally contains 5 ordered scales: very good, good, fair, poor, and very poor. } & $\begin{array}{l}0=\text { very good and } \\
\text { good }\end{array}$ & $40.96 \%$ \\
\hline & & $\begin{array}{l}1=\text { very poor, poor } \\
\text { and fair }\end{array}$ & $59.04 \%$ \\
\hline \multirow[t]{2}{*}{$\begin{array}{l}\text { Cognitive } \\
\text { impairment }\end{array}$} & \multirow[t]{2}{*}{$\begin{array}{l}\text { It is measured with the Chinese version of the Mini-Mental State Examination (MMSE); the } \\
\text { total score range is } 0-30 \text {. }\end{array}$} & $\begin{array}{l}0=\text { MMSE score } \\
\text { less than } 18\end{array}$ & $77.02 \%$ \\
\hline & & $\begin{array}{l}1=\text { MMSE more } \\
\text { than } 18\end{array}$ & $22.98 \%$ \\
\hline \multirow[t]{2}{*}{$\begin{array}{l}\text { Difficulty } \\
\text { with ADLs }\end{array}$} & \multirow[t]{2}{*}{$\begin{array}{l}\text { It includes } 6 \text { indexes: bathing, dressing, using the toilet, indoor walking, eating, and getting up } \\
\text { and down. }\end{array}$} & $\begin{array}{l}0=\text { no difficulty } \\
\text { with any of the six } \\
\text { ADLs }\end{array}$ & $75.64 \%$ \\
\hline & & $\begin{array}{l}1 \text { = difficulty with } \\
\text { any of the six } \\
\text { ADLs }\end{array}$ & $24.36 \%$ \\
\hline \multirow[t]{2}{*}{$\begin{array}{l}\text { Difficulty } \\
\text { with IADLs }\end{array}$} & \multirow[t]{2}{*}{$\begin{array}{l}\text { It includes } 8 \text { indexes: visiting neighbours, going shopping, making food, washing clothes, } \\
\text { walking one kilometre, carrying } 5 \mathrm{~kg} \text { weight, crouching and standing three times, and taking } \\
\text { public transportation. }\end{array}$} & $\begin{array}{l}0=\text { no difficulty } \\
\text { with any of the } \\
\text { eight IADLs }\end{array}$ & $36.63 \%$ \\
\hline & & $\begin{array}{l}1 \text { = difficulty with } \\
\text { any of the eight } \\
\text { IADLs }\end{array}$ & $63.37 \%$ \\
\hline \multicolumn{4}{|c|}{ Independent variable } \\
\hline $\begin{array}{l}\text { Short-term } \\
\text { social } \\
\text { isolation }\end{array}$ & Those who became socially isolated between 2011 and 2014 & & \\
\hline \multirow[t]{2}{*}{ Spouseless } & \multirow[t]{2}{*}{ Those who became widowed/divorced between 2011 and 2014} & $0=$ no & $96.28 \%$ \\
\hline & & $1=$ yes & $3.72 \%$ \\
\hline \multirow[t]{2}{*}{ Childless } & \multirow[t]{2}{*}{ Those who became childless between 2011 and 2014} & $0=$ no & $97.36 \%$ \\
\hline & & $1=$ yes & $2.64 \%$ \\
\hline \multirow{2}{*}{$\begin{array}{l}\text { Have no } \\
\text { siblings }\end{array}$} & \multirow[t]{2}{*}{ Those who lost all siblings between 2011-2014 } & $0=$ no & $90.91 \%$ \\
\hline & & $1=$ yes & $9.99 \%$ \\
\hline \multirow{2}{*}{$\begin{array}{l}\text { Isolated } \\
\text { from social } \\
\text { activities }\end{array}$} & \multirow[t]{2}{*}{ Those who withdrew from social activities between 2011 and 2014} & $0=$ no & $93.11 \%$ \\
\hline & & $1=$ yes & $6.89 \%$ \\
\hline \multirow[t]{2}{*}{ Loneliness } & \multirow[t]{2}{*}{ Those who reported loneliness between 2011 and 2014} & $0=$ no & $96.79 \%$ \\
\hline & & $1=$ yes & $3.21 \%$ \\
\hline $\begin{array}{l}\text { Long-term } \\
\text { social } \\
\text { isolation }\end{array}$ & Social isolation status in 2011 & & \\
\hline \multirow[t]{2}{*}{ Spouseless } & \multirow[t]{2}{*}{ Those who were already widowed/divorced in 2011} & $0=$ no & $48.41 \%$ \\
\hline & & $1=$ yes & $51.59 \%$ \\
\hline \multirow[t]{2}{*}{ Childless } & \multirow[t]{2}{*}{ Those who were already childless in 2011} & $0=$ no & $97.92 \%$ \\
\hline & & $1=$ yes & $2.08 \%$ \\
\hline \multirow{2}{*}{$\begin{array}{l}\text { Have no } \\
\text { siblings }\end{array}$} & \multirow[t]{2}{*}{ Those who already had no siblings in 2011} & $0=$ no & $69.11 \%$ \\
\hline & & $1=$ yes & $30.89 \%$ \\
\hline \multirow{2}{*}{$\begin{array}{l}\text { Isolated } \\
\text { from social } \\
\text { activities }\end{array}$} & \multirow[t]{2}{*}{ Those who did not participate in social activities in 2011} & $0=$ no & $28.55 \%$ \\
\hline & & $1=$ yes & $71.45 \%$ \\
\hline \multirow[t]{2}{*}{ Loneliness } & \multirow[t]{2}{*}{ Those who reported loneliness in 2011} & $0=$ no & $99.03 \%$ \\
\hline & & $1=$ yes & $0.97 \%$ \\
\hline
\end{tabular}




\begin{tabular}{|c|c|c|c|}
\hline Variable & Description & Coding & $\begin{array}{l}\text { Percentage/Mean } \\
(\mathrm{N}=6,066)\end{array}$ \\
\hline Age & & $\begin{array}{l}\operatorname{Min}=65 \operatorname{Max}= \\
114\end{array}$ & Mean $=85.78$ \\
\hline \multirow[t]{2}{*}{ Gender } & & $0=$ female & $54.96 \%$ \\
\hline & & $1=$ male & $45.04 \%$ \\
\hline \multirow{3}{*}{$\begin{array}{l}\text { Self-rated } \\
\text { SES }\end{array}$} & \multirow[t]{3}{*}{ Self-rated socioeconomic status } & 1 = lower & $15.54 \%$ \\
\hline & & 2 = fair & $67.29 \%$ \\
\hline & & 3 = higher & $17.17 \%$ \\
\hline Education & Years of schooling & $\operatorname{Min}=0 \operatorname{Max}=24$ & Mean $=2.45$ \\
\hline \multirow[t]{2}{*}{ Residence } & \multirow[t]{2}{*}{ Living in the rural area } & $0=$ no & $47.31 \%$ \\
\hline & & $1=$ yes & $52.69 \%$ \\
\hline \multirow[t]{2}{*}{ Smoking } & \multirow[t]{2}{*}{ Smoke at present } & $0=$ no & $82 \%$ \\
\hline & & $1=$ yes & $17.93 \%$ \\
\hline \multirow[t]{2}{*}{ Drinking } & \multirow[t]{2}{*}{ Drink at present } & $0=$ no & $82.93 \%$ \\
\hline & & $1=$ yes & $17.06 \%$ \\
\hline $\begin{array}{l}\text { Leisure } \\
\text { activities }\end{array}$ & $\begin{array}{l}\text { It includes } 3 \text { indexes: gardening, reading, and watching TV. The score range of each item is } \\
\text { from } 0-4 \text {, presenting the frequency of doing the leisure activities: never, sometimes, monthly, } \\
\text { weekly, every day. }\end{array}$ & $\operatorname{Min}=0 \operatorname{Max}=12$ & Mean $=3.78$ \\
\hline \multirow{2}{*}{$\begin{array}{l}\text { Physical } \\
\text { exercise }\end{array}$} & \multirow[t]{2}{*}{ Exercise at present } & $0=$ no & $66.80 \%$ \\
\hline & & $1=$ yes & $33.15 \%$ \\
\hline
\end{tabular}

\section{Multivariate Results}

\section{The short-term effects of social isolation on health outcomes}

Table 2 presents the logistic regression models of the short-term effects of social isolation on reporting poor SRH, cognitive impairment, and having difficulty with ADLs and IADLs. The results show that older people who newly became spouseless were less likely to have cognitive impairment (odds ratios [ORs] = 0.71 , Model 1), but the effect becomes insignificant after controlling for covariates of demographic, socioeconomic, lifestyle, and baseline health status factors (Model 2). Older people who newly became childless were more likely to report poor SRH and cognitive impairment (ORs = 1.65 and 7.68, Model 1), and these associations remain significant after controlling for covariates (ORs = 1.53 and 9.87, Model 2). Meanwhile, older people who newly became childless were more likely to have difficulty with $A D L s(O R=1.63$, Model 1$)$, but this association became statistical non-significant after controlling for covariates (Model 2). Older people who newly lost their siblings were more likely to report poor SRH, cognitive impairment, and difficulty with ADLs and IADLs (ORs $=1.29$, $1.23,1.26$ and 1.28 respectively, Model 1$)$, and these associations remain significant after controlling for covariates $(\mathrm{ORs}=1.29,1.35,1.26$ and 1.22 respectively, Model 2). Notably, older people who withdrew from social activities were less likely to report poor SRH, cognitive impairment, difficulty with ADLs and IADLs (ORs $=0.86,0.65,0.80$, and 0.83 , Model 1 ), but these associations become insignificant after controlling for covariates (Model 2). Lastly, older people who reported loneliness were more likely to report poor SRH and difficulties with IADLs (ORs $=2.14$ and 1.60 , Model 1$)$, and these associations remain significant after controlling for covariates (ORs = 1.92 and 1.55, Model 2). 
Table 2

Short-term effects of social isolation on SRH, cognitive impairment, difficulty with ADLs, difficulty with IADLs.

\begin{tabular}{|c|c|c|c|c|c|c|c|}
\hline & \multicolumn{2}{|c|}{ Poor SRH-2014 } & \multicolumn{2}{|c|}{ Cognitive impairement-2014 } & \multicolumn{2}{|c|}{ Difficulty with ADLs-2014 } & \multirow{2}{*}{$\begin{array}{l}\text { Difficulty with } \\
\text { model1 }\end{array}$} \\
\hline & model1 & model2 & model1 & model2 & model1 & model2 & \\
\hline & ORs $(95 \% \mathrm{Cl})$ & ORs $(95 \% \mathrm{Cl})$ & ORs $(95 \% \mathrm{Cl})$ & ORs $(95 \% \mathrm{Cl})$ & ORs $(95 \% \mathrm{Cl})$ & ORs $(95 \% \mathrm{Cl})$ & ORs $(9$ \\
\hline \multicolumn{8}{|c|}{$\begin{array}{l}\text { Social isolation at family } \\
\text { level }\end{array}$} \\
\hline \multirow[t]{2}{*}{ Spouseless } & 1.139 & 1.136 & $0.713^{\star}$ & 0.810 & 1.022 & 1.186 & 1.249 \\
\hline & $(0.907,1.432)$ & $(0.902,1.431)$ & $(0.517,0.982)$ & $(0.580,1.131)$ & $(0.769,1.358)$ & $(0.883,1.591)$ & $(0.963,1.619)$ \\
\hline \multirow[t]{2}{*}{ Childless } & $1.651^{*}$ & $1.528^{*}$ & $7.677^{\star \star \star *}$ & $9.867 * \star \star$ & $1.633^{*}$ & 1.169 & 1.576 \\
\hline & $(1.127,2.418)$ & $(1.040,2.245)$ & $(5.745,10.26)$ & $(7.105,13.70)$ & $(1.061,2.513)$ & $(0.747,1.828)$ & $(0.999,2.486)$ \\
\hline \multirow[t]{2}{*}{ No siblings } & $1.288^{\star \star}$ & $1.294^{\star \star}$ & $1.231^{*}$ & $1.350 * \star$ & $1.257^{\star}$ & $1.257^{\star}$ & $1.279 \star \star$ \\
\hline & $(1.104,1.502)$ & $(1.107,1.513)$ & $(1.024,1.479)$ & $(1.111,1.640)$ & $(1.045,1.513)$ & $(1.036,1.524)$ & $(1.072,1.526)$ \\
\hline \multicolumn{8}{|c|}{ Social isolation at societal level } \\
\hline \multirow{2}{*}{$\begin{array}{l}\text { Deficiency } \\
\text { in } \\
\text { participating } \\
\text { in social } \\
\text { activities }\end{array}$} & 0.860 & 0.992 & $0.651^{\star \star \star}$ & 0.953 & 0.800 & 1.020 & $0.826^{\star}$ \\
\hline & $(0.725,1.019)$ & $(0.832,1.183)$ & $(0.506,0.838)$ & $(0.724,1.253)$ & $(0.634,1.010)$ & $(0.797,1.305)$ & $(0.684,0.999)$ \\
\hline \multicolumn{8}{|l|}{ Loneliness } \\
\hline & $2.114^{\star \star \star}$ & $1.923^{\star \star \star}$ & 1.181 & 1.103 & 0.853 & 0.864 & $1.604^{\star \star}$ \\
\hline & $(1.609,2.776)$ & $(1.461,2.530)$ & $(0.871,1.602)$ & $(0.803,1.515)$ & $(0.618,1.177)$ & $(0.618,1.207)$ & $(1.195,2.154)$ \\
\hline \multicolumn{8}{|c|}{$\begin{array}{l}\text { Notes: Model 1, unadjusted model. Model 2, adjusted for age, gender, self-rated SES, education, rural area, smoking, alcohol drinking, physical exercise, leisur } \\
\text { health status (measured in 2011) of SRH, MMSE, ADLs, and IADLs. }\end{array}$} \\
\hline \multicolumn{8}{|c|}{ * $P<0.05$, ** $P<0.01$, *** $P<0.001$} \\
\hline
\end{tabular}

\section{The long-term effects of social isolation on health outcomes}

Table 3 presents the logistic regression models of the long-term effects of social isolation on poor SRH, cognitive impairment, and difficulty with ADLs and IADLs in 2014. Similar to Table 2, Model 1s in Table 3 report the effects of objective and subjective social isolation at the baseline on health outcomes in 2014, and Model 2s additionally include the covariates of demographic, socioeconomic, lifestyle, and baseline health status factors. 
Table 3

Long-term effects of social isolation on SRH, cognitive impairment, difficulty with ADLs, difficulty with IADLs.

\begin{tabular}{|c|c|c|c|c|c|c|c|c|}
\hline & \multicolumn{2}{|c|}{ Poor SRH-2014 } & \multicolumn{2}{|c|}{ Cognitive impairement-2014 } & \multicolumn{2}{|c|}{ Difficulty with ADLs-2014 } & \multicolumn{2}{|c|}{ Difficulty with IADLs-2014 } \\
\hline & model1 & model2 & model1 & model2 & model1 & model2 & model1 & model2 \\
\hline & ORs $(95 \% \mathrm{Cl})$ & ORs $(95 \% \mathrm{Cl})$ & ORs $(95 \% \mathrm{Cl})$ & ORs $(95 \% \mathrm{Cl})$ & ORs $(95 \% \mathrm{Cl})$ & ORs $(95 \% \mathrm{Cl})$ & ORs $(95 \% \mathrm{Cl})$ & ORs $(95 \% \mathrm{Cl})$ \\
\hline \multicolumn{9}{|c|}{ Social isolation at family level } \\
\hline \multirow[t]{2}{*}{ Spouseless } & 1.107 & 0.944 & 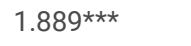 & 0.850 & $1.724^{\star \star \star}$ & 0.902 & $2.193^{\star \star \star}$ & 1.085 \\
\hline & $(0.990,1.239)$ & $(0.829,1.076)$ & $(1.631,2.188)$ & $(0.714,1.012)$ & $(1.487,1.998)$ & $(0.757,1.074)$ & $(1.925,2.498)$ & $(0.933,1.263)$ \\
\hline \multirow[t]{2}{*}{ Childless } & 1.171 & 1.059 & 0.760 & 0.716 & 0.926 & 1.035 & 0.945 & 1.389 \\
\hline & $(0.779,1.761)$ & $(0.700,1.603)$ & $(0.472,1.225)$ & $(0.424,1.209)$ & $(0.568,1.508)$ & $(0.609,1.756)$ & $(0.595,1.501)$ & $(0.821,2.350)$ \\
\hline \multirow[t]{2}{*}{ No siblings } & 1.109 & 1.029 & $1.968^{\star \star \star}$ & $1.211^{\star}$ & $1.708^{\star \star \star}$ & 1.114 & $1.815^{\star \star \star}$ & 1.177 \\
\hline & $(0.982,1.252)$ & $(0.905,1.170)$ & $(1.706,2.269)$ & $(1.034,1.418)$ & $(1.473,1.980)$ & $(0.948,1.309)$ & $(1.562,2.109)$ & $(0.998,1.387)$ \\
\hline \multicolumn{9}{|c|}{ Social isolation at societal level } \\
\hline \multirow{2}{*}{$\begin{array}{l}\text { Deficiency in } \\
\text { participating in } \\
\text { social activities }\end{array}$} & $1.486^{\star \star \star}$ & $1.329 * * \star$ & $1.197^{\star}$ & 0.890 & $1.764^{\star \star \star}$ & 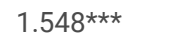 & 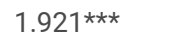 & $1.689 \star \star \star$ \\
\hline & $(1.315,1.680)$ & $(1.165,1.515)$ & $(1.015,1.412)$ & $(0.740,1.070)$ & $(1.476,2.109)$ & $(1.275,1.879)$ & $(1.672,2.206)$ & $(1.449,1.970)$ \\
\hline \multicolumn{9}{|l|}{ Loneliness } \\
\hline & $3.193^{\star \star}$ & $2.959 * \star$ & 0.796 & 0.961 & 0.216 ** & $0.318^{*}$ & 1.551 & $2.447^{\star}$ \\
\hline & $(1.491,6.839)$ & $(1.381,6.338)$ & $(0.399,1.590)$ & $(0.472,1.956)$ & $(0.0736,0.631)$ & $(0.108,0.938)$ & $(0.725,3.318)$ & $(1.109,5.400)$ \\
\hline \multicolumn{9}{|c|}{$\begin{array}{l}\text { Notes: Model 1, unadjusted model. Model 2, adjusted for age, gender, self-rated SES, education, rural area, smoking, alcohol drinking, physical exercise, } \\
\text { leisure activities, and baseline health status (measured in 2011) of SRH, MMSE, ADLs, and IADLs. }\end{array}$} \\
\hline \multicolumn{9}{|c|}{ * $P<0.05$, ** $P<0.01$, *** $P<0.001$} \\
\hline
\end{tabular}

The results show that older people who were already spouseless in 2011 were significantly more likely to have cognitive impairment, and difficulty with ADLs and IADLs in 2014 than their counterparts who lived with a spouse (ORs = 1.89, 1.72 and 2.19, respectively, Model 1), nevertheless, all associations become statistically insignificant after controlling for demographic, socioeconomic, and lifestyle covariates (Model 2). Meanwhile, no significant differences are found for the long-term effects of childlessness in 2011 on having poor SRH, cognitive impairment, and difficulty with ADLs or IADLs in 2014. Older people who had no siblings in 2011 were more likely to have cognitive impairment than those who had surviving siblings in 2011 (OR = 1.97, Model 1), and this association remain significant after controlling for covariates $(O R=1.21$, Model 2). Meanwhile, older people who had no siblings in 2011 were more likely to have difficulty with ADLs and IADLs in 2014 (ORs = 1.71 and 1.82, Model 1), but theses associations became statistically insignificant after controlling for covariates (Model 2). Older people who did not participate social activities in 2011 were more likely to report poor SRH, difficulty with ADLs and IADLs in 2014 than those who participated social activities in 2011 (ORs $=1.49,1.76$ and 1.92, respectively, Model 1), and these associations remain significant after controlling for covariates $(\mathrm{ORs}=1.33,1.55$ and 1.69, respectively, Model 2). While, the significant associations with higher odds on cognitive impairment for those did not participate social activities in 2011 (OR = 1.20, Model 1) became insignificant after controlling for covariates (Model 2). Finally, older people who reported loneliness in 2011 were more likely to report poor SRH and difficulty with IADLs in 2014 (ORs = 3.19 and 1.55, Model 1), and these associations remain significant after controlling for covariates (ORs = 2.96 and 2.45, Model 2). However, older people who reported loneliness in 2011 were less likely to report difficulties in ADLs in 2014 (OR = 0.22, Model 1), and this association remain significant after controlling for covariates $(\mathrm{OR}=0.32$, Model 2).

\section{Discussion}

This study investigates the short-term and long-term effects of objective social isolation and subjective social isolation on various health outcomes of older people in China.

The short-term effects of social isolation refer to situations in which older people become spouseless, childless, lose their siblings, do not participate in social activities, or experience loneliness, newly within the last three years.

Meanwhile, the long-term effects of social isolation refer to situations in which older people had already become spouseless, childless, without siblings, not participating in social activities, or experienced loneliness at the baseline (three or more years ago).

The results show that objective social isolation at family level have short-term effects rather than long-term effects on older people's health outcomes. With considering all the covariates of demographic, socioeconomic, lifestyle, and baseline health status factors, newly becoming childless was significantly associated with being more likely to report poor SRH and cognitive impairment in the short term, but childless status at baseline was not significantly associated with any of the health outcomes mentioned above. Meanwhile, the loss of siblings also had significant short-term effects on all four health outcomes; however, the long-term effect of being without siblings at the baseline was significantly associated only with cognitive impairment. Previous studies found that support from children was older people's main option in later life in China (Liu \& Feng, 2019); thus, the absence of children could reduce older people's health comprehensively, which was reflected in deteriorated SRH and cognitive impairment in the short term. When older people can access 
social support from social security as replacement for support from their children, the detrimental effects of childlessness on health outcomes could be minimised. As a result, the long-term effects of childlessness on health outcomes becomes insignificant (Feng, 2018). In addition, siblings are often the "key people" who combine frequent contact, strong commitment, and the performance of a range of instrumental tasks, especially for those who are not married or have no children (Bigby, 1997). The absence of siblings may be one of the reasons of inadequate social contacts which could impact on older people's health outcomes comprehensively. In short, the detrimental effects of absence of family members on older people's health outcomes could be mostly short term. As time goes by, the effects become insignificant, or can be explained by demographic, socioeconomic, and lifestyle covariates, and baseline health status.

In terms of the objective social isolation at societal level, older people who withdrew from social activities in the short term were less likely to report poor SRH, cognitive impairment, difficulty with ADLs, and difficulty with IADLs. This is in accordance with previous studies, which suggested that social activities may increase older people's risk of getting injuries (Wang et al., 2020), and therefore that older people might try to avoid social activities to protect themselves. Moreover, these short-term effects of withdrawing from social activities on health outcomes could be explained by the covariates of demographic, socioeconomic, lifestyle, and baseline health status factors. Notwithstanding, older people who did not participate in social activities were more likely to have poor SRH, and difficulty with ADLs and IADLs in the long term, after controlling for covariates. This indicates that being isolated from social activities for a long time could gradually erode older people's functional abilities.

Regarding to subjective social isolation, loneliness had both short-term and long-term effects on SRH. This suggests that subjective social isolation could impact on older people's health through a psychological pathway by breaking their sense of belonging and social connection, with the effects not merely appearing in the short term, but also lasting in the long term. These findings partly reinforce previous research showing that subjective social isolation is important for older people's SRH (Feng et al., 2019). Moreover, both short-term and long-term effects of loneliness result in older people's lower abilities to perform IADLs, which suggests that loneliness could reduce their willingness to do the relatively more complicated daily living activities, such as going shopping and visiting neighbours. Meanwhile, the long-term effect of loneliness is associated with older people's higher abilities to perform ADLs. Older people who feel lonely would expect that no one would help them due to the absence of feelings of belonging and having fulfilling relationships, so they may have to develop better abilities to perform ADLs to live independently.

\section{Limitations}

This study also has its limitations. First, the definitions of the short term and the long term are limited to the period between two waves of CLHLS: three years, in this study. The short-term and long-term effects could be longer or shorter than three years. Second, this study is limited by the information of how long older people had been socially isolated, such as how long they had been spouseless, childless, or without anyone when in need. The accumulation of the negative effects of social isolation may be underestimated. Third, this study only includes the latest two waves of CLHLS. Although there are 5 more earlier waves of CLHLS, the sample size was largely decreased by including more waves due to the death of respondents and lost-to-follow in longer period followups. Nevertheless, despite these limitations, this analysis provides important insights into the short-term and long-terms effects of social isolation on health outcomes among older people in China.

\section{Implications}

Our study found that objective social isolation and subjective social isolation were both associated with worse health outcomes among older Chinese, but the implications were different. Objective social isolation at family level mainly had short-term impacts rather than long-term impacts on older people's health outcomes; while objective social isolation at societal level had long-term impacts on older people's health outcomes. Timely medical and social service support would be needed if an older person is newly experiencing the absence of family members.

Meanwhile, for older people who withdrew from social activities, social service could help to continuously encourage and design long-term plans for them to participate in social activities gradually.

In terms of subjective social isolation, loneliness had both short-term and long-term effects on increasing the risk of reporting poor SRH. It is important to provide emotional support for an older person who feels lonely; psychological advice may also help to prevent the adverse effects of loneliness on older people's health outcomes.

Future research on these topics should pay more attention on the interventions to older people who are or had experience of being social isolated. Health interventions are increasingly needed to focus on how to support older people with social isolation - because social isolation has both short-term and longterms effects on different health outcomes, particularly for those who have experiences of "feeling lonely" or losing a spouse, child, or siblings due to COVID19. Prospective studies can assess the short-term and long-term effects of interventions to prevent the adverse effects of social isolation on older people's health outcomes.

\section{Declarations}

\section{Data availability}

The datasets used during the current study are available from the corresponding author on reasonable request.

\section{Competing interests}

The authors declare that they have no competing interests.

\section{Funding}


This work was supported by China Postdoctoral Science Foundation (NO. 2019M663338), and National Social Sciences Foundation of China (19CRK005).

\section{Authors' contributions}

Z.Y., and Z.F. designed the research and directed its implication; Z.Y. prepared and analyzed the data; Z.Y. drafted the manuscript; all co-authors revised the manuscript together.

\section{Acknowledgement}

We are grateful to the CLHLS study, which provided the data in this research. The CLHLS was supported by funds from the U.S. National Institute of Aging of National Institute of Health, the Duke/Duke-NUS Collaboration Pilot Project, the China Natural Science Foundation, the China Social Science Foundation and the United Nations Fund for Population Activities (UNFPA) and was managed by the Center for Healthy Aging and Development Studies, Peking University.

\section{References}

Antonovsky A (1987). Unravelling the Mystery of Health: How People Manage Stress and Stay Well. Jossey-Bass, San Francisco.

Beland F, Zunzunegui M. V, Alvarado B, Otero A and Del Ser T (2005). Trajectories of cognitive decline and social relations. The Journals of Gerontology Series B: Psychological Sciences and Social Sciences 60, P320-P330.

Berkman L (1983). The assessment of social networks and social support in the elderly. Journal of the American Geriatrics Societa/31, 743-749.

Berkman L (1984). Assessing the physical health effects of social networks and social support. Annual Review of Public Health 5, $413-432$.

Boden-Albala B, Litwak E, Elkind S, Rundek T and Sacco L (2005). Social isolation and outcomes post stroke. Neurology 64, 1888-1892.

Bigby C (1997). When parents relinquish care: informal support networks of older people with intellectual disability. Journal of Applied Research in Intellectual Disabilities 10, 333-344.

Cacioppo T, Cacioppo S, Capitanio P and Cole W (2015). The neuroendocrinology of social isolation. Annual Review of Psychology 66, $733-767$.

Chen S and You (2019). Life Restoration and Future Care Preparation Among Older Parents in Shanghai Who Have Lost Their Only Adult Child. Journal of Applied Gerontology 00, 1-18.

Chen L, Ye M and Kahana E (2020). A self-reliant umbrella: defining successful aging among the old-old (80+) in Shanghai. Journal of Applied Gerontology 39, 242-249.

Chapman P, Perry S and Strine W (2005). The Vital Link Between Chronic Disease and Depressive Disorders. Preventing Chronic Disease 2, 1-10.

Coyle C. E and Dugan E (2012). Social isolation, loneliness and health among older adults. Journal of Aging and Health 24, $1346-1363$.

Douglas (2020). The Costs of Social Isolation: Loneliness and COVID-19. General Psychiatry. https://www.psychiatryadvisor.com/home/topics/generalpsychiatry/costs-of-social-isolation-loneliness-covid19/[Accessed on 24/6/2020]

Eng M, Rimm B, Fitzmaurice G and Kawachi I (2002). Social ties and change in social ties in relation to subsequent total and cause-specific mortality and coronary heart disease incidence in men. American Journal of Epidemiology 155, 700-709.

Evandrou M, Falkingham J, Feng Z and Vlachantoni A (2014). Individual and province inequalities in health among older people in China: evidence and policy implications. Health \& Place 30, 134-144.

Feng Z (2018). Childlessness and vulnerability of older people in China. Age and Ageing 47, 275-281.

Feng Z, Jones K and Phillips R (2019). Social exclusion, self-rated health and depression among older people in China: evidence from a national survey of older persons. Archives of Gerontology and Geriatrics 82, 238-244.

Gierveld J and Van T (2006). A 6-item scale for overall, emotional, and social loneliness confirmatory tests on survey data. Research of Aging 28 , 582-598.

Hartigan I, Cornally N, Foley T, Timmons S, Park G, Jennings A and Muller N (2019). Exploring the Complexity of Dementia and Loneliness in Ireland. Age and Ageing 48, 302-314.

House J.S, Landis K, Umberson D (1988). Social relationships and health. Science 241, 540-545.

House J. S (2001). Social isolation kills, but how and why? Psychosomatic medicine 63, 273-274.

Howat P, Iredell H, Grenade L, Nedwetzky A and Collins J (2004). Reducing social isolation amongst older people implications for health professionals. Geriaction 22, 13-20.

Kiecolt-Glaser, Janice K, Tamara L and Newton (2001). Marriage and Health: His and Hers. Psychological Bulletin 127, $472-503$. 
Kluge (2020). Older people are at highest risk from COVID-19, but all must act to prevent community spread. World Health Organization Statement. http://www.euro.who.int/en/health-topics/health-emergencies/coronavirus-covid-19/statements/statement-older-people-are-at-highest-risk-from-covid-19,-butall-must-act-to-prevent-community-spread [Accessed on 24/6/2020]

Li T and Zhang Y. L (2015). Social network types and the health of older adults: exploring reciprocal associations. Social Science and Medicine $130,59-68$.

Li M. and Dai H. (2019). Determining the primary caregiver for disabled older adults in mainland China: spouse priority and living arrangements. Journal of Family Therapy 41, 126-141.

Liu and Feng (2019). Support for Older People in Households with Bare Branches in Rural China: Vulnerability, Dilemmas, and Possible Solutions. Journal of Applied Gerontology 00, 1-8.

McEwen S. (1998). Stress, adaptation, and disease: allostasis and allostatic load. Annals of the New York Academy of Sciences 840, 33-44.

Nicholson R. (2009). Social isolation in older adults: an evolutionary concept analysis. Journal of Advanced Nursing 65, $1342-1352$.

Nguyen T, Black A, Ray A, Espino V and Markides S (2003). Cognitive impairment and mortality in older Mexican Americans. Journal of the American Geriatrics Societal 51, 178-183.

Peplau L. A and Perlman D (1982). Loneliness:A sourcebook of current theory, research and therapy. New York: Wiley Interscience.

Phillips R and Feng Z (2015). Challenges for the ageing family in the People's Republic of China. Canadian Journal on Aging 34, $290-304$.

Rubin D (1976). Inference and Missing Data. Biometrika 63, 581-592.

Seeman T. E, Singer B. H, Ryff C. D, Dienberg, Love G and Levy-Storms L (2002). Social relationships, gender, and allostatic load across two age cohorts. Psychosomatic Medicine 64, 395-406.

Sereny M and G D (2011). Living Arrangement Concordance and Its Association with Self-Rated Health Among Institutionalized and Community-Residing Older Adults in China. Journal of Cross-Cultural Gerontology 26, 239-259.

Stone J, Evandrou M and Falkingham J (2013). The transition to living alone and psychological distress in later life. Age and Ageing 42, 366-372.

Taylor H. O, Robert J. T, Nguyen A.W and Chatters L (2018). Social isolation, depression, and psychological distress among older adults. Journal of Aging and Health 30, 229-246.

Wang R, Feng Z, Liu Y and Lu Y (2020). Relationship between neighbourhood social participation and depression among older adults: a longitudinal study in China. Health and Social Care in the Community 28, 247-259.

World Health Organization. (2007). Global age-friendly cities: A guide.

http://www.who.int/ageing/publications/Global_age_friendly_cities_Guide_English.pdfZeng Y, Feng Q, Hesketh T, Christensen K and Vaupel W (2017). Survival, disabilities in activities of daily living, and physical and cognitive functioning among the oldest-old in China: a cohort study. The Lancet 389 , 16191629.

Zhang X, Zahner E, Roman C, Liu H, Wu B and Hong Z, et al. (2006). Socio-demographic variation of dementia subtypes in China: methodology and results of a prevalence study in Beijing, Chengdu, Shanghai, and Xi'an. Neuroepidemiology 27, 177-187.

Zhang Z, Gu D and Hayward D (2010). Childhood nutritional deprivation and cognitive impairment among older Chinese people. Social Science and Medicine 71, 941-949. 